\title{
What is the role of rhenium in single crystal superalloys?
}

\author{
Alessandro Mottura ${ }^{1, a}$ and Roger C. Reed ${ }^{2,3}$ \\ ${ }^{1}$ School of Metallurgy and Materials, University of Birmingham, Edgbaston B15 2TT, UK \\ ${ }^{2}$ Engineering Science Department, University of Oxford, Oxford OX1 3PJ, UK \\ ${ }^{3}$ Materials Department, University of Oxford, Oxford OX1 3PH, UK
}

\begin{abstract}
Rhenium plays a critical role in single-crystal superalloys -its addition to first generation alloys improves creep life by a factor of at least two, with further benefits for fatigue performance. Its use in alloys such as PWA1484, CMSX-4 and Rene N5 is now widespread, and many in this community regard Re as the "magic dust". In this paper, the latest thinking concerning the origins of the "rhenium-effect" is presented. We start by reviewing the hypothesis that rhenium clusters represent barriers to dislocation motion. Recent atom probe tomography experiments have shown that Re may instead form a solid solution with $\mathrm{Ni}$ at low concentrations $(<7$ at.\%). Density functional theory calculations indicate that, in the solid solution, short range ordering of Re may be expected. Finally, Re has been shown to diffuse slowly in the $\gamma$-Ni phase. Calculations using a semi-analytical dislocation climb/glide model based upon the work of McLean and Dyson have been used to rationalise the composition-dependence of creep deformation in these materials. All evidence points to two important factors: (i) the preferred partitioning of $\operatorname{Re}$ to the $\gamma$ phase, where dislocation activity preferentially occurs during the tertiary creep regime and (ii) a retardation effect on dislocation segments at $\gamma / \gamma^{\prime}$ interfaces, which require non-conservative climb and thus an associated vacancy flux.
\end{abstract}

\section{Introduction}

Rhenium additions are essential for the high-temperature properties of single-crystal superalloys. The higher performance of superalloys have resulted in longer-lasting components and higher fuel efficiencies. Re has been so important to the industry that single-crystal superalloys are commonly grouped into generations based on their Re content: first-generation Re-free alloys gave way to secondgeneration alloys in the 1990s, containing 2-3wt.\% $\mathrm{Re}$, superseded by third-generation alloys in the 2000s, containing 5-6 wt.\% Re.

Since the advent of third-generation alloys, engine manufacturers have opted to reduce Re content in their alloys, primarily due to cost concerns: $\mathrm{Re}$ is one of the most expensive transition metals. Its average price between 2000 and 2010 has been US\$3000/kg, and the price is likely to increase in future. The high price means that Re alone can be, depending on the alloy, responsible for over half of the raw material cost needed to produce turbine blades. In addition, the use of Re also poses a risk due to the fact that the majority of Re reserves are clustered in a limited number of countries.

The high price of $\mathrm{Re}$, and its importance as a strategic element, underline the need for the community to understand the role of $\operatorname{Re}$ on the high-temperature properties of Ni-based superalloys, with the objective of designing new grades of alloys with lower Re content or completely Re-free. In this paper, after describing the beneficial effects of $\mathrm{Re}$ additions to the high-temperature

${ }^{\mathrm{a}}$ Corresponding author: a.mottura@bham.ac.uk properties of Ni-based superalloys, we examine all the available experimental evidence and discuss its significance in conjunction to recent modelling efforts.

\section{The rhenium-effect}

The earliest evidence of $\mathrm{Re}$ additions to the Ni-based superalloys can be found in a 1975 patent submitted by Smashey [1]. The objective of Smashey's work was to improve the high-temperature properties of a unidirectionally solidified eutectic Ni-based superalloys by precipitating fibrous carbide phases aligned with the growth direction [1]. In these high-C superalloys, Re (contrary to $\mathrm{W}$ ) is not a carbide former and can therefore be used to strengthen the matrix phase and promote the partitioning of elements such as Ta and $\mathrm{V}$ to the $\gamma^{\prime}$ phase [1]. Research efforts on investigating the effect of Re additions on carbide-strengthened directionally-solidified Ni-based superalloys continued through the beginning of 1980s [2], when the advent of single-crystal Ni-based superalloys changed the field dramatically.

The first attempts to add Re to single-crystal specimens were made by Giamei and reported in [3]. In this work, Giamei modified MAR-M200 (Ni-5Al-2Ti-1Nb$9 \mathrm{Cr}-12 \mathrm{~W}$ wt. $\%$ ) by adding Re instead of $\mathrm{W}$, keeping the $\mathrm{W}+\mathrm{Re}$ weight concentration fixed. From the base alloy, hereafter called alloy $0 \mathrm{Re}$, three other compositions were obtained: $2 \mathrm{Re}, 4 \mathrm{Re}$ and $6 \mathrm{Re}$, containing 2,4 and 6 wt.\% Re respectively. These compositions were grown as single-crystal along the [001] direction, using a modified Bridgman technique. The resulting specimens were tested in creep at $899^{\circ} \mathrm{C}$ under a load of $380 \mathrm{MPa}$, revealing the 


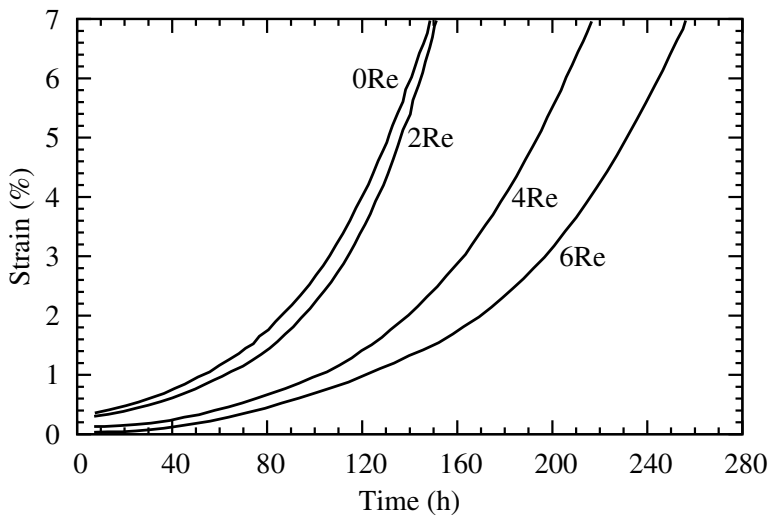

Figure 1. Creep curves for alloy 1444 and Re-containing derivatives at $899^{\circ} \mathrm{C}$ under a load of $380 \mathrm{MPa}$ [3].

creep behaviour that can be observed in Figure 1. Since this initial report, the dramatic beneficial effects of $\mathrm{Re}$ additions on tertiary creep deformation has been confirmed in various single-crystal alloys [4-6], and is commonly referred to as the rhenium-effect.

Beside the improved tertiary creep lives of Recontaining alloys, Re additions have been observed to considerably reduce the coarsening kinetics of $\gamma^{\prime}$ precipitates [7], primarily due to the fact that Re strongly favours partitioning to the $\gamma$ phase. The strong partitioning of Re to the $\gamma$ phase has been observed in most single-crystal Ni-based superalloys with high $\gamma^{\prime}$ volume content [4,8-10], and it is supported by first-principles calculations showing $\mathrm{Re}$ substitutional defects are unstable in the $\gamma^{\prime}$ phase [11]. As the $\gamma^{\prime}$ precipitates coarsen, Re has to diffuse ahead of the $\gamma / \gamma^{\prime}$ interface [7]. The strong partitioning of Re to the $\gamma$ phase, coupled with the fact that Re is the slowest-diffusing transition metal in $\mathrm{Ni}$ [12-14], means that $\gamma^{\prime}$ coarsening rates are severely limited by the presence of Re. This is also beneficial, as slower $\gamma^{\prime}$ coarsening kinetics result in longer rupture lives at elevated temperatures, when rafting (i.e. directional coarsening) becomes problematic [7]. This behaviour was also later confirmed and discussed in great detail by the work of Seidman et al. [15-18].

Whereas the effect of $\operatorname{Re}$ on the $\gamma^{\prime}$ coarsening kinetics can be clearly attributed to the partitioning characteristic of $\mathrm{Re}$ and its diffusion coefficient in $\mathrm{Ni}$, the strengthening effect of Re additions on tertiary creep has been the subject of wider discussion, which we hope to summarise here.

\section{Summary of evidence}

\subsection{One-dimensional atom probe}

Blavette and co-workers pioneered the use of atom probe analysis to study the behaviour of $\mathrm{Re}$ in Ni-based superalloys $[4,19]$. In this work, the one-dimensional version of the tool (1DAP) was used to examine the solute distribution in PWA 1480, CMSX-2, PWA 1480-Re (with a nominal 4 wt.\% Re and no W) and CMSX-2-4Re (containing 4 wt.\% Re and 4 wt.\% W). Creep tests carried out at $850^{\circ} \mathrm{C}$ and $500 \mathrm{MPa}$ revealed a 30-40\% increase in rupture life associated with the addition of Re. The atom probe analysis confirmed that the Re atoms strongly partition to the $\gamma$ matrix phase, leaving the $\gamma^{\prime}$ precipitates
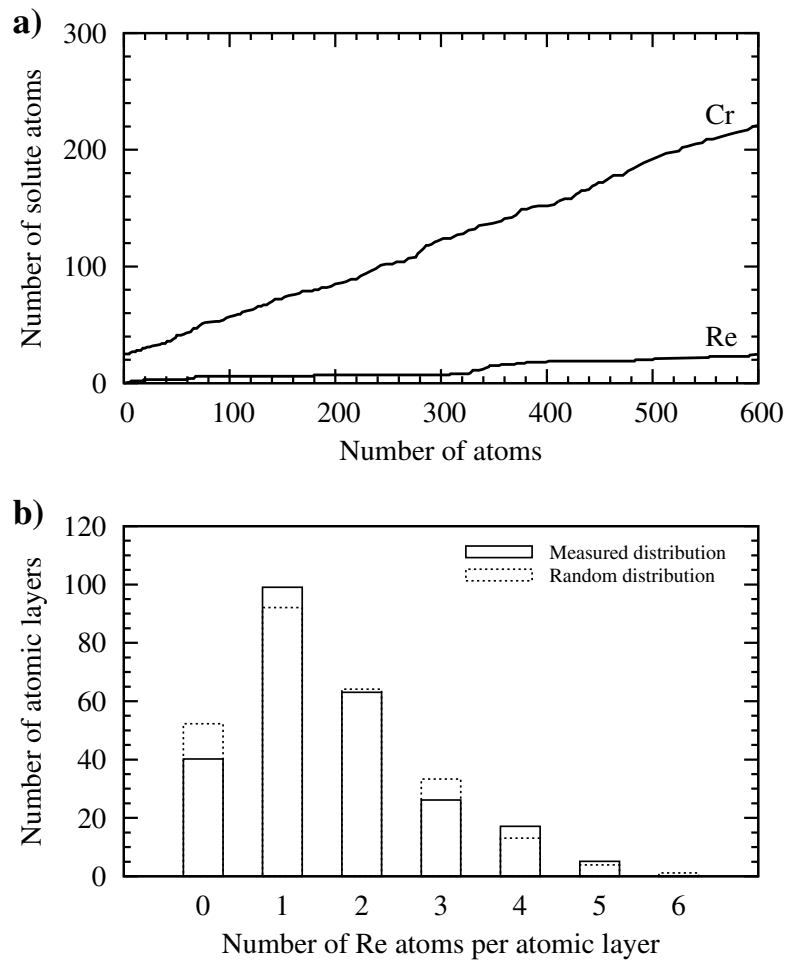

Figure 2. a) Cumulative profile of $\mathrm{Re}$ showing spatial irregularities and b) histogram of the number of atomic layers containing a given number of Re atoms [4].

depleted of Re content. The Re content in the $\gamma$ phased ranged from 2.87 at.\% to 3.71 at.\% for CMSX-2-4Re and PWA 1480-Re respectively.

The atom probe also revealed irregularities in the spatial distribution of Re: cumulative profiles (see Fig. 2a) of $\mathrm{Re}$ desorption indicated the presence of areas with higher Re content [4]. In order to quantify the spatial distribution of Re, Blavette and co-workers plotted a histogram of the number of atomic layers containing a set number of Re atoms, and compared that to a Poisson's random distribution (see Fig. 2b). A larger number of atomic layers contained 1, 4 or $5 \mathrm{Re}$ atoms than expected from a random distribution, while fewer atomic layers contained 0, 2, 3 or $6 \mathrm{Re}$ atoms than expected from a random distribution [4]. It is arguable whether this is evidence for either short range ordering or clustering of Re atoms in the $\gamma$ phase of Ni-based superalloys. The authors proposed the evidence collected proved the presence of Re clusters, $1-1.5 \mathrm{~nm}$ in size, that contained up to 90 at.\% Re [4, 19], suggesting this would be expected when considering the large miscibility gap in the established Ni-Re binary phase diagram [20,21]. It follows that these clusters would act as powerful barriers against dislocation glide when compared to distributed $\mathrm{Re}$ atoms in solid solution with $\mathrm{Ni}$.

Following the initial atom probe work by Blavette et al., Wanderka and Glatzel also used the 1DAP to study the distribution of Re in CMSX-4 [22]. Also in this case, cumulative profiles of Re revealed fluctuations in $\mathrm{Re}$ distribution, and a comparison of the Re distribution of a Poisson's distribution revealed a lower than expected number of atomic layers containing 0 and $3 \mathrm{Re}$ atoms, while a higher than expected number of atomic layers 

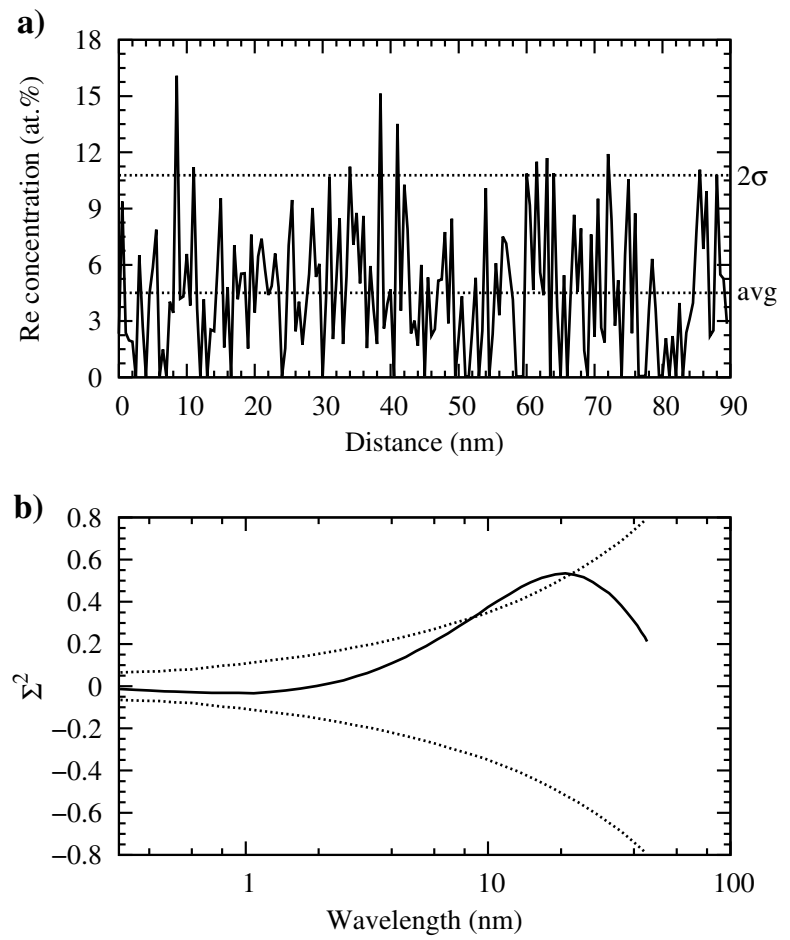

Figure 3. a) Compositional profile of $\operatorname{Re}$ along $1.5 \times 1.5 \times$ $90 \mathrm{~nm}$ volume and b) results of the wavelength dependent filtering method on a $1.5 \times 1.5 \times 90 \mathrm{~nm}$ volume [23].

contained 1 or $2 \mathrm{Re}$ atoms [22]. The authors indicated this as evidence of clusters, suggesting these are likely to be composed by $5 \mathrm{Re}$ atoms, 3 in one atomic layer, with an additional atom in the upper and lower layer [22]. The pioneering work in these early studies was limited by the capabilities of the 1DAP.

\subsection{Three-dimensional atom probe}

The advent of the three-dimensional atom probe (3DAP) allowed for a more complete investigation of the distribution of Re in the superalloys. Warren et al used a 3DAP to study the Re distribution in the $\gamma$ phase and at the $\gamma / \gamma^{\prime}$ interfaces of RR3000, a Re-containing third-generation Ni-based superalloy [8]. Along with the strong partitioning of $\operatorname{Re}$ to the $\gamma$ phase, the authors found Re-enriched areas near the interfaces of the secondary and tertiary $\gamma^{\prime}$ precipitates, on the $\gamma$ phase side [8]. These would be expected since, upon cooling from higher temperatures, the secondary $\gamma^{\prime}$ precipitates grow and tertiary $\gamma^{\prime}$ precipitates are expected to form in the middle of the $\gamma$ channels, ejecting $\mathrm{Re}$ ahead of their interfaces. The authors found no evidence of Re clusters in their samples [8].

Rüsing et al. argued for the presence of Re clusters in their samples of Re31, a model quaternary alloy [23]. In their work, a long and thin volume $(1.5 \times 1.5 \times$ $90 \mathrm{~nm}$ ) was divided into slices $0.5 \mathrm{~nm}$ thick in order to obtain a one-dimensional concentration profile, revealing slices where the local Re concentration exceeded $2 \sigma$ (see Fig. 3a) [23]. As this approach would not conclusively demonstrate the presence of clusters, the authors adopted the wavelength dependent filtering method. This approach, based on Fourier analysis, can be used to investigate the

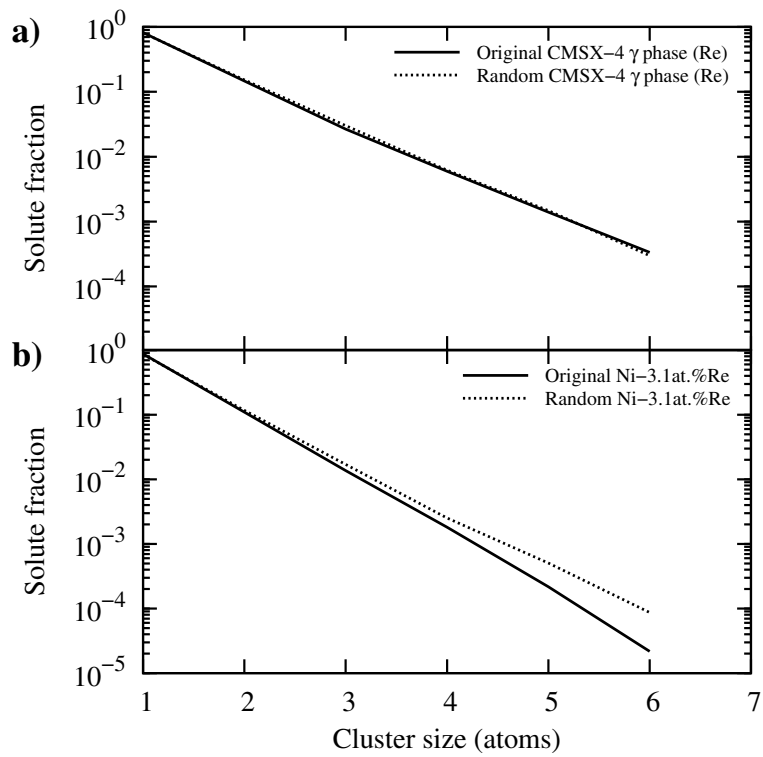

Figure 4. The results of the maximum-separation friends-offriends algorithm on a) the $\gamma$ phase of CMSX-4 and b) a Ni-Re binary alloy, showing Re distribution to be consistent with a solid solution [25].

heterogeneity of the data, without providing any indication of the shape and size of these heterogeneities. This analysis indicated that $\mathrm{Re}$ is heterogeneously distributed with a principal wavelength of $20 \mathrm{~nm} \mathrm{[23]} \mathrm{(see} \mathrm{Fig.} \mathrm{3b),} \mathrm{but}$ the heterogeneities observed may also be due to an nonhomogeneous distribution of Re.

Recently, more 3DAP studies have been carried out to determine whether Re clusters may be present in the $\gamma$ phase of Ni-based superalloys [24,25]. A number of Ni$\mathrm{X}$ binary alloys (where $\mathrm{X}$ is Ta, $\mathrm{W}, \mathrm{Re}, \mathrm{Ir}$ and $\mathrm{Pt}$ ), with $10 \mathrm{wt} \%$ nominal solute content, were analysed using a direct-flightpath 3DAP. A maximum-separation friends-offriends algorithm was used to evaluate the presence of $\mathrm{Re}$ clusters in the data. The results were compared to simulated atom probe datasets [24] and randomised versions of themselves [25] (see Fig. 4). No clusters were detected. The same approach was adopted to study the distribution of Re in the $\gamma$ phase of CMSX-4 where, similarly to the binary alloys, clusters were not found [24,25]. A sensitivity analysis of the approach on simulated 3DAP datesets revealed that sparse clusters $\left(3.5 \cdot 10^{24} \mathrm{~m}^{-3}\right)$ with $1 \mathrm{~nm}$ diameter should be evident, even when considering the detection efficiency and spatial resolution of the tool [24,25].

\subsection{Other experimental evidence}

Ge et al. studied the distribution of $\mathrm{Re}$ in the $2^{\text {nd }}$ generation single-crystal superalloys DD6 using high angle annular dark field (HAADF) and energy dispersive spectroscopy (EDS) on a scanning transmission electron microscope (STEM) [26]. Chemical analysis across the $\gamma / \gamma^{\prime}$ interface revealed no Re enrichment in the un-crept specimens, whereas $\mathrm{Re}$ enriched areas were present in the crept specimens, suggesting these form only after considerable $\gamma^{\prime}$ particle coarsening occurring during creep tests [26]. The authors also proposed that high-contrast areas observed near the $\gamma / \gamma^{\prime}$ interfaces after the creep tests 
could be evidence of Re/W clusters 1-2 nm in diameter [26]. However, these high-contrast areas could also be due to expected compositional fluctuations.

The presence of $\mathrm{Re}$ clusters in the $\mathrm{Ni}$ lattice was also investigated using extended x-ray absorption fine spectroscopy (EXAFS) [27,28]. In EXAFS, the local atomic structure surrounding atoms of a specific element can be probed by examining the oscillations in x-ray absorption coefficient immediately above the absorption edge of that element. In this case, the $\mathrm{L}_{3}$ edge of Re was used to detect the local environment surrounding the $\mathrm{Re}$ atoms in the specimens. Both studies clearly indicate that Re-Re first neighbour pairs are unlikely in the Ni lattice, as the data clearly indicates that Re is coordinated by $12 \mathrm{Ni}$ atoms $[27,28]$.

Diffusion couple studies have conclusively shown that $\mathrm{Re}$ is one of the slowest-diffusing transition metals in $\mathrm{Ni}[12,13]$. When compared to other solute elements commonly added to the superalloys, Re is shown to diffuse almost an order-of-magnitude slower than W [12]. The general trends observed showed that elements sitting in the middle of the transition metal series diffuse slower than the elements at the edges of the transition metal series, despite being smaller in size [13].

\section{The modelling contribution}

\subsection{Density functional theory}

$\mathrm{Ab}$ initio density functional theory (DFT) proved instrumental in understanding and explaining why elements in the middle of the $4 d$ and $5 d$ transition metal series diffuse slower than elements at the edges of it $[14,29]$. In contrast to the outer elements, such as Hf and $\mathrm{Au}$, elements in the middle of the $5 d$ transition metal series, such as $\mathrm{Re}$, form directional $d$ bonds with the surrounding $\mathrm{Ni}$ atoms. These directional $d$ bonds are less compressible, and result in a higher energy barrier for the Re to exchange position with a neighbouring vacancy $[14,29]$. This explains the higher activation energy for diffusion observed for the smallest atoms in the middle of the $4 d$ and $5 d$ transition metal series [14,29].

Calculations of binding energies of $\operatorname{Re}-\operatorname{Re} 1^{\text {st }}$ and higher-order pairs using DFT reveal that Re clusters would be energetically unfavourable [30]. Investigation of the $\mathrm{Ni}-\mathrm{Re} 0 \mathrm{~K}$ formation energy hull indicates that $\mathrm{Ni}_{4} \mathrm{Re}$ $\left(\mathrm{D} 1_{\mathrm{a}}\right)$ and $\mathrm{NiRe}_{3}\left(\mathrm{DO}_{19}\right)$ should be stable at absolute zero [31,32]. High-throughput DFT calculations were also used to parameterise a cluster expansion to determine the effect of configurational entropy on the free energy of the relevant phases through a Monte Carlo approach $[31,33]$. Results indicate that the $\mathrm{Ni}_{4} \mathrm{Re}\left(\mathrm{D} 1_{\mathrm{a}}\right)$ intermetallic would not be stable above $600-700^{\circ} \mathrm{C}$ due to the effects of configurational entropy. Including vibrational entropy would result in a further reduction of the $\mathrm{Ni}_{4} \mathrm{Re}\left(\mathrm{D} 1_{\mathrm{a}}\right)$ solvus temperature [33]. Considering the activation energy of $\mathrm{Re}$ diffusion in $\mathrm{Ni}$, it is reasonable to expect this phase not to form except after very long heat treatments. Above the solvus temperature of the $\mathrm{Ni}_{4} \mathrm{Re}\left(\mathrm{D} 1_{\mathrm{a}}\right)$ intermetallic, the Monte Carlo simulations predict that relatively low concentrations of $\operatorname{Re}(0-7$ at. \%) can form a solid solution with Ni [33]. Simulated X-ray diffuse scattering data reveals remnant short-range ordering of $\mathrm{Re}$ in $\mathrm{Ni}$, which gradually reduces as temperature is increased due to configurational entropy [33]. Clustering of Re atoms in the $\mathrm{Ni}$ lattice is predicted to be energetically unfavourable at all temperatures [33].

\subsection{Microstructure evolution models}

Yoon et al investigated the effect of Re additions on the temporal evolution of Re-free and Re-containing model $\mathrm{Ni}-\mathrm{Al}-\mathrm{Cr}$ superalloys by comparing experimental data, obtained using 3DAP and TEM, to calculations made with the Umantsev-Olson model and PrecipiCalc ${ }^{\mathrm{TM}}[16,17]$. In their alloys, Ni-8.5Cr-10Al, Ni-8.5Cr-10Al-2Re and $\mathrm{Ni}-8.5 \mathrm{Cr}-10 \mathrm{Al}-2 \mathrm{~W}$ (at.\%), the authors did not observe any bow-wave or monotonic Re-enrichment at the $\gamma / \gamma^{\prime}$ interfaces, at all ageing times [16,17]. This is possibly due to the fact that specimens were water quenched, resulting in a smaller migration of the $\gamma / \gamma^{\prime}$ interface upon cooling. Other factors, such as a lower volume fraction of $\gamma^{\prime}$ phase compared to single-crystal commercial Nibased superalloys, and a finer distribution of spherical precipitates may have also played a role on the absence of a monotonic Re-enrichment at the $\gamma / \gamma^{\prime}$ interfaces. Coarsening of the $\gamma^{\prime}$ precipitates during ageing did not cause the formation of a Re-enrichment at the $\gamma / \gamma^{\prime}$ interfaces, although both experiments and simulations showed that the addition of Re resulted in a considerable deceleration of coarsening kinetics $[16,17]$.

Warnken used phase field simulations to establish whether the Re enrichment observed close to the $\gamma / \gamma^{\prime}$ interfaces of uncrept CMSX-4 specimens [24,25] should be attributed to the coarsening of the $\gamma^{\prime}$ secondary precipitates during heat treatment or to the growth of the $\gamma^{\prime}$ secondary precipitates when cooling from service temperature. Simulations were made using the MICRESS ${ }^{\mathrm{TM}}$, coupling the Thermo-Tech ${ }^{\mathrm{TM}}$ TTNI version 6 database and the NIST $\mathrm{Ni}$ superalloy mobility database to accurately represent the thermodynamics and kinetics of CMSX-4. The migration of the $\gamma / \gamma^{\prime}$ interface upon cooling from $950^{\circ} \mathrm{C}$ to $650^{\circ} \mathrm{C}$ was shown to be strongly dependent on cooling rates [25]. The migration of the $\gamma / \gamma^{\prime}$ interface upon cooling resulted in a bow-wave ahead of the interface, comparable to that observed in CMSX-4 using the 3DAP [25]. Subsequent heating simulations caused the $\gamma / \gamma^{\prime}$ interface to retreat and the Re composition close to the $\gamma / \gamma^{\prime}$ interfaces to rehomogenise [25]. It was concluded that no Re enrichment would be present at service temperature near the $\gamma / \gamma^{\prime}$ interfaces of CMSX-4 [25].

\section{Discussion: A modern view of the role of rhenium in superalloys}

A number of mechanisms contribute to the beneficial effects of Re additions on the high-temperature properties of Ni-based superalloys. Perhaps the most important of these is the partitioning behaviour of $\operatorname{Re}$ to the $\gamma$ matrix phase. This has been observed in most Re-containing singlecrystal commercial Ni-based superalloys. Whenever the partitioning of Re to the $\gamma$ phase was not observed, the high-temperature properties were unaffected by small $\mathrm{Re}$ additions [34]. Although only relatively small amounts 
of $\operatorname{Re}(0-2$ at. \%) are sufficient to produce a two-fold increase in creep life, contributing to its fame as a "magic dust", it is important to note that most of the Re will partition to the minority phase $(\gamma)$, where the resultant concentration of Re may be as high as 7 at.\%. Thanks to its partitioning behaviour and its low diffusion coefficient, small $\mathrm{Re}$ additions are very effective in retarding the $\gamma^{\prime}$ coarsening and rafting kinetics, thereby extending creep life at the higher temperatures $\left(>1000^{\circ} \mathrm{C}\right)$. This, however, is not sufficient to explain the improved tertiary creep regime properties associated with the addition of $\mathrm{Re}$ to single-crystal Ni-based superalloys.

Therefore, Re must play a role on the deformation processes occurring in the $\gamma$ phase during the tertiary creep regime. Under these conditions, dislocations glide in the $\gamma$ phase and stop at the $\gamma / \gamma^{\prime}$ interfaces, since stresses are not high enough to allow penetration and cutting of the $\gamma^{\prime}$ precipitates. To continue on their path, these dislocations must move along the $\gamma / \gamma^{\prime}$ interface by a thermally-activated climb process $[35,36]$. Re must act as an effective barrier to dislocation motion. This process cannot be dismissed as a simple solute-strengthening mechanism as it has been shown that $\mathrm{Re}$ is a poor solid-solution strengthener in $\mathrm{Ni}[37,38]$. Furthermore, single solute atoms do not pose a considerable barrier to dislocation glide at elevated temperatures. Small Re clusters could stop dislocation glide in the $\gamma$ phase, but experimental evidence of their presence is not conclusive. Small inhomogeneities of the Re distribution have been observed in the $\gamma$ phase of a variety of alloys, but these may be a natural occurrence in a multi-component solid-solution where composition is highly inhomogeneous due to the microstructure and manufacturing route. Examination of simpler Ni-Re binary specimens provided no evidence of the presence of Re clusters, despite state-of-the-art cluster-detection algorithms were used. Similar conclusions were drawn when examining the Re distribution in the $\gamma$ of CMSX-4.

Density functional theory conclusively shows that ReRe first-neighbour pairs and small first- and secondneighbour clusters would be unstable in Ni. Further studies of the formation energy convex hull reveal an intermetallic with chemical formula $\mathrm{Ni}_{4} \mathrm{Re}$ and crystal structure $\mathrm{D} 1_{\mathrm{a}}$ may be stable at absolute zero, but configurational and vibrational entropy effects mean that this intermetallic would only form below $600-700^{\circ} \mathrm{C}$, or not form at all due to the slow diffusion of Re. The fact that this intermetallic may only form under specific cooling conditions may explain some of the conflicting atom probe results; regardless, calculations unequivocally show such a phase would not be present at service temperature, and cannot explain the anomalous strengthening effect caused by $\mathrm{Re}$ additions on tertiary creep.

Since atoms of Re cannot pose a sufficient barrier to dislocation glide, and Re clusters are not present at service temperature, the reason for the rhenium-effect must be sought elsewhere. In tertiary creep, the motion of dislocations is controlled by the climb rate at the $\gamma / \gamma^{\prime}$ interfaces. Climb is a thermally activated process that requires solute atoms to exchange position with vacancies at the dislocation core. In addition, depending on the climbing direction, a dislocation may act as a vacancy emitter or absorber (see Fig. 5). Therefore, the surplus of

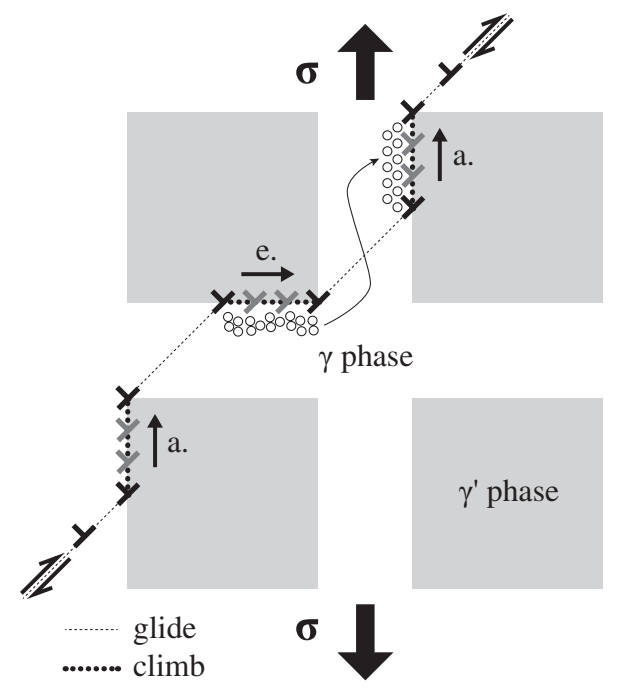

Figure 5. A 2D schematic of the climb-assisted glide process occurring in tertiary creep and the resulting vacancy flow from the horizontal to the vertical channels [35].

vacancies in areas where the climb of dislocations results in the generation of vacancies have to diffuse to areas where the climb of dislocations results in the absorption of vacancies (see Fig. 5). As a slow diffuser, Re would act to slow both of these processes, reducing the overall climb rate. A semi-analytical dislocation climb/glide model based upon the work of McLean and Dyson has been used to test this hypothesis [35]. The results indicate that the arithmetic average of the solvent and solute diffusion coefficients, weighted by their atomic concentrations, is a good first order approximation for the effective vacancy diffusion coefficient, and qualitatively captures the effects of $\gamma$ phase composition on tertiary creep.

\section{Conclusions}

1. Small additions of Re have been shown to dramatically improve the high-temperature creep properties, specifically within the tertiary creep regime.

2. The mechanisms underlying the anomalous creep strengthening contribution of Re to the superalloys are still unclear.

3. It is well known that Re reduces the coarsening and rafting of the $\gamma / \gamma^{\prime}$ microstructure, but this alone is not enough to explain the improved tertiary creep behaviour of $2^{\text {nd }}$ - and $3^{\text {rd }}$-generation alloys.

4. Initial evidence suggested Re may form clusters in the $\gamma$ phase of Ni-based superalloys. These clusters could act as barriers to dislocation motion.

5. The theory that Re forms clusters is not supported by the latest 3DAP and EXAFS result which, instead, suggest that Re forms a solid solution with $\mathrm{Ni}$.

6. Electronic structure calculations have shown that small Re clusters are unstable in Ni. An intermetallic compound with formula $\mathrm{Ni}_{4} \mathrm{Re}$ may be stable from absolute zero up to intermediate temperatures, but $\mathrm{Re}$ is expected to form a solid solution with $\mathrm{Ni}$ above $600-700^{\circ} \mathrm{C}$. The Ni-Re solid solution may be characterised by some remnant short-range ordering. 
7. The consolidated hypothesis is that creep deformation at elevated temperature is controlled by climb-assisted glide, where the temperatureactivated climb mechanism is rate-controlling.

8. Re additions must act to slow down the necessary flow of vacancies and other atomic-scale diffusion mechanisms required for climb to happen. This, together with the fact that most Re atoms partition to the $\gamma$ phase, is enough to explain the beneficial effects of Re on creep life in the tertiary creep regime.

9. Further work is necessary to place this hypothesis on a firm quantitative basis, and explicitly link the chemical composition of the $\gamma$ phase to the creep life in the tertiary regime.

\section{References}

[1] R. Smashey, Patent no. 3,904, 402 (1975)

[2] D.L. Anton, F.D. Lemkey, Quinary alloy modifications of the eutectic superalloys $\gamma / \gamma^{\prime}+\mathrm{Cr}_{3} \mathrm{C}_{2}$, in Superalloys 1984, edited by M. Gell, C.S. Kortovich, R.H. Bricknell, W.B. Kent, J.F. Radavich (The Minerals, Metals and Materials Society, Warrendale, PA, USA, Seven Springs, PA, USA, 1984), pp. 601610

[3] A.F. Giamei, AFOSR Annual Report FR-11009 (1978)

[4] D. Blavette, P. Caron, T. Khan, Scripta Metallurgica 20, 1395 (1986)

[5] S. Wöllmer, T. Mack, U. Glatzel, Materials Science and Engineering A 319-321, 792 (2001)

[6] R.C. Reed, The superalloys: fundamentals and applications (Cambridge University Press, 2006)

[7] A.F. Giamei, D.L. Anton, Metallurgical and Materials Transactions A 16, 1997 (1985)

[8] P.J. Warren, A. Cerezo, G.D.W. Smith, Materials Science and Engineering A 250, 88 (1998)

[9] A. Volek, R.F. Pyczak, R.F. Singer, H. Mughrabi, Scripta Materialia 52, 141 (2005)

[10] Y. Zhou, Z. Mao, C. Booth-Morrison, D.N. Seidman, Applied Physics Letters 93, 171905 (2008)

[11] Y.J. Wang, C.Y. Wang, Journal of Applied Physics 104, 013109 (2008)

[12] M.S.A. Karunaratne, P. Carter, R.C. Reed, Materials Science and Engineering A 281, 229 (2000)

[13] M.S.A. Karunaratne, R.C. Reed, Acta Materialia 51, 2905 (2003)

[14] A. Janotti, M. Krcmar, C.L. Fu, R.C. Reed, Physical Review Letters 92, 085901 (2004)

[15] D. Isheim, G. Hsieh, R.D. Noebe, D.N. Seidman, Nanostructural temporal evolution and solute partitioning in model Ni-based superalloys containing ruthenium, rhenium and tungsten, in Solid-to-solid phase transformations in Inorganic Materials 2005, edited by J. Howe, D. Laughlin, J. Lee, U. Dahmen, W. Soffa (The Minerals, Metals and Materials Society, Warrendale, PA, USA, 2005), Vol. 1, pp. 309-314

[16] K.E. Yoon, R.D. Noebe, D.N. Seidman, Acta Materialia 55, 1145 (2007)

[17] K.E. Yoon, R.D. Noebe, D.N. Seidman, Acta Materialia 55, 1159 (2007)
[18] D.N. Seidman, C.K. Sudbrack, K.E. Yoon, JOM 58, 34 (2006)

[19] D. Blavette, P. Caron, T. Khan, An atom-probe study of some fine-scale microstructural features in Ni-based single crystal superalloys, in Superalloys 1988, edited by S. Reichman, D. N. Duhl, G. Maurer, S. Antolovich, C. Lund (The Minerals, Metals and Materials Society, Warrendale, PA, USA, 1988), pp. 305-314

[20] D. Blavette, E. Cadel, B. Deconihout, Materials Characterization 44, 133 (2000)

[21] D. Blavette, E. Cadel, C. Pareige, B. Deconihout, P. Caron, Microscopy and Microanalysis 13, 464 (2007)

[22] N. Wanderka, U. Glatzel, Materials Science and Engineering A 203, 69 (1995)

[23] J. Rüsing, N. Wanderka, U. Czubayko, V. Naundorf, D. Mukherji, J. Rösler, Scripta Materialia 46, 234 (2002)

[24] A. Mottura, M.K. Miller, R.C. Reed, Atom probe tomography analysis of possible rhenium clustering in nickel-based superalloys, in Superalloys 2008, edited by R.C. Reed, P. Caron, T. Gabb, E. Huron, S. Woodare (The Minerals, Metals and Materials Society, Warrendale, PA, USA, Seven Springs, PA, USA, 2008), pp. 891-900

[25] A. Mottura, N. Warnken, M.K. Miller, M.W. Finnis, R.C. Reed, Acta Materialia 58, 931 (2010)

[26] B.H. Ge, Y.S. Luo, J.R. Li, J. Zhu, Scripta Materialia 63, 969 (2010)

[27] A. Mottura, R.T. Wu, M.W. Finnis, R.C. Reed, Acta Materialia 56, 2669 (2008)

[28] V. Koteski, H.E. Mahnke, J. Belosevic-Cavor, B. Cekic, G. Schumacher, Acta Materialia 56, 4601 (2008)

[29] C.L. Fu, R.C. Reed, A. Janotti, M. Krcmar, On the diffusion of the solutes in the superalloys, in Superalloys 2004, edited by K.A. Green, T.M. Pollock, H. Harada, T.E. Howson, R.C. Reed, J.J. Schirra, S. Walston (The Minerals, Metals and Materials Society, Warrendale, PA, USA, 2004), pp. 189-195

[30] A. Mottura, M.W. Finnis, R.C. Reed, Acta Materialia 60, 2866 (2012)

[31] N. Schindzielorz, Ph.D. thesis, Technische Universität Hamburg-Harburg (2013)

[32] O. Levy, M. Jahnatek, R.V. Chepulskii, G.L.W. Hart, S. Curtarolo, Journal of the American Chemical Society 133, 158 (2011)

[33] S.B. Maisel, N. Schindzielorz, A. Mottura, R.C. Reed, S. Müller, Advanced Materials (submitted) (2014)

[34] V. Kindrachuk, N. Wanderka, J. Banhard, D. Mukherji, D. Del Genovese, J. Rösler, Acta Materialia 56, 1609 (2008)

[35] Z. Zhu, H. Basoalto, N. Warnken, R.C. Reed, Acta Materialia 60, 4888 (2012)

[36] S.M. Hafez Haghighat, G. Eggeler, D. Raabe, Acta Materialia 61, 3709 (2013)

[37] K. Durst, M. Göken, Materials Science and Engineering A 387-389, 312 (2004)

[38] B. Gan, S. Tin, Materials Science and Engineering A 527, 6809 (2010) 